Encontro Nacional de

Economia Industrial e Inovação
Indústria e Desenvolvimento Econômico:

desafios e perspectivas

18 a 20 de setembro de 2018

Uberlândia - Minas Gerais

\title{
TRANSFORMAÇÕES NOS FLUXOS DE COMÉRCIO INTERNACIONAL: UMA AVALIAÇÂO DO DESEMPENHO DO SETOR INDUSTRIAL E DE SERVIÇO
}

\author{
Vinicius C.B. Fornari \\ Doutor em Economia pela Universidade Estadual de Campinas (UNICAMP) e Pesquisador \\ Colaborador do Grupo de Estudos \\ em Economia Industrial (GEEIN). \\ Rogério Gomes \\ Professor do Departamento de Economia da Universidade Estadual Paulista (Unesp) e Coordenador \\ do Grupo de Estudos em \\ Economia Industrial (GEEIN).
}

RESUMO: $\mathrm{O}$ artigo examina as relações comerciais entre as principais economias mundiais para avaliar e comparar o desempenho do setor industrial e de serviço. Esse exame é realizado por meio dos indicadores de redes, ressaltando as diferenças entre os países desenvolvidos (PD) e países em desenvolvimento (PeD) nos anos de 1995 e 2010. Os resultados mostram que existe uma desconcentração do comércio internacional, para os $\mathrm{PeD}$, atrelado principalmente ao crescimento chinês, como fornecedor industriais e como consumidor de serviços ofertados pelos PD. Adicionalmente, mostra-se que a indústria tem alavancado o comércio internacional dos serviços para a maioria dos países da amostra.

Palavras-chave: comércio internacional; relações intersetoriais; indústria; serviços; análise de redes.

\begin{abstract}
The article examines the trade relations between the world's major economies to evaluate and compare the performance of the industrial sector and service. This survey is carried out through network indicators, highlighting the differences between developed and developing countries in the years 1995 and 2010. The results show that there is a deconcentration of international trade for developing countries, mainly linked to Chinese growth, as an industrial supplier and as a consumer of services offered by the developed countries. In addition, it has been shown that industry has leveraged international trade in services for most of the sampled countries.
\end{abstract}

Keywords: international trade; intersectoral relations; industry; services; network analysis.

JEL: F15; F18; O14 


\section{Introdução}

As modificações nos setores de serviços relacionadas à crescente especialização, terceirização e à incorporação de serviços nas atividades industriais têm reflexos no potencial de agregação de valor dessas atividades nas economias e nas relações internacionais. Nas últimas décadas a intensificação da estratégia de internacionalização de empresas de países desenvolvidos (PD) para países em desenvolvimento $(\mathrm{PeD})$ fomentou uma nova divisão internacional do trabalho: aqueles que detêm as funções manufatureiras, os que se especializaram em certos serviços e os que mesclam as duas soluções. Esses arranjos foram determinantes para as transformações no direcionamento (países), magnitude (valores) e pauta (tipo de bem ou serviço) do comércio internacional nos últimos anos.

O objetivo deste artigo é examinar as mudanças nas relações comerciais entre diferentes países e avaliar, principalmente, o desempenho dos setores da indústria de transformação e serviços. A avaliação foi realizada por meio dos indicadores propostos para as doze maiores economias do mundo (segundo o PIB de 2010: Alemanha, Brasil, China, Coreia, EUA, França, Índia, Itália, Japão, México, Reino Unido e Rússia), ressaltando as diferenças entre os países desenvolvidos (PD) e países em desenvolvimento (PeD) nos anos de 1995 e 2010, com especial destaque para as interações entre a indústria de transformação e os serviços.

Considerando que que este estudo privilegia o exame das relações entre as atividades de serviços e industriais, as economias nacionais são consideradas segundo três agregados (Recursos Naturais, contemplando a Agricultura e Pesca e Extrativa Mineral; Indústria de Transformação; Construção); Construção e Serviços. Essa classificação é extraída da World Input-Output Database (WIOD, 2014) ${ }^{1}$, fontes das estatísticas utilizadas (matrizes insumos importados das contas nacionais).

Além desta introdução, o artigo foi dividido em mais quatro seções. A seção 1 revisita a literatura para abordar as mudanças no comércio internacional, com especial ênfase àquelas relativas às atividades de serviços. Através de dados da matriz insumo-produto do comércio internacional, a seção seguinte avalia as transformações no agregado dos países PD e PeD. Na seção 3, por meio do método de redes e dados da matriz de comércio internacional, comparamos as redes de relações dos países ressaltando as diferenças e semelhanças, principalmente entre os grupos de PD e PeD. Os comentários finais são apresentados na seção 4.

\section{Transformações nos Fluxos de Comércio Internacional e as Atividades Industriais e de Serviços}

O comércio internacional passou por diversas transformações nas últimas décadas, desde aquelas relacionadas às magnitudes (valores monetários e quantidades) e ao número de países participantes (direcionamento dos fluxos) até a composição da pauta de comércio (aumento da participação dos serviços). Para Hiratuka (2002) esse processo está associado principalmente a três fenômenos: i) os efeitos do progresso tecnológico, relacionados às novas tecnologias e produtos e dos seus efeitos sobre a produtividade; ii) o processo de liberalização comercial, no âmbito multilateral destaque para a rodada Uruguai do Acordo Geral de Tarifas e Comércio (GATT, na sigla em inglês) e o surgimento e consolidação da Organização Mundial do Comércio (OMC), no âmbito regional com os acordos de livre comércio e de uniões aduaneiras; que possibilitaram a redução das barreiras comerciais, e; iii) as mudanças observadas nas formas de atuação e organização das atividades internacionais das grandes empresas transnacionais (ETNs). Em particular, este último fenômeno é

\footnotetext{
${ }^{1}$ A indústria agrega quatorze setores: Alimentos, Bebidas e Tabaco, Têxteis e produtos têxteis, Couro e Calçado, Madeira, produtos de madeira e cortiça, Celulose, Papel e Impressão, Coque, Petróleo refinado e Combustível Nuclear, Substâncias e produtos químicos, Borracha e Plástico, Outros minerais não metálicos, Metalurgia e produtos de metal, Máquinas e Equipamentos, Equipamentos Elétricos e Ópticos, Equipamentos de Transporte, Reciclagem e Diversos.

O agregado serviços é comporto por serviços é comporto por quatro segmentos: Distribuição; Sociais, Pessoais; Produtivos
} 
apontado por diferentes estudos como aspecto determinante tanto nas alterações do direcionamento dos fluxos, quanto para pauta comercial. Somente o comércio intrafirma (entre partes da mesma companhia em diferentes países) representa cerca de 1/3 do total mundial (IETTO-GILLIES, 2012; cap 2).

Desde a década de 1980, o aumento do Investimento Direto Estrangeiro (IDE), mecanismo de expansão das empresas transnacionais (ETNs), vem adensando os fluxos do comércio mundial de bens e serviços (UNCTAD, 2007). O crescimento do comércio internacional inter e intrafirma está fortemente vinculado às estratégias das ETNs, crescentemente voltadas para organizar, especializar e integrar de forma mais eficiente a produção internacional cada vez mais dispersa (GEREFFI et al., 2005; MANYIKA et al.., 2012).

Ao longo da década de 1980 e início da década seguinte, as variações nos fluxos de comércio acompanharam os de IDE e, em especial, o estoque de IDE. Entretanto, após a segunda metade dos anos 1990 e reforçado no começo do século XXI ocorre um deslocamento entre a primeira e as duas últimas taxas de crescimento - os fluxos de IDE e de fusões e aquisições (F\&A) se tornam mais instáveis após a crise de 2007-2008. Este deslocamento pode estar refletindo a consolidação - ao menos temporária - da globalização enquanto processo de "dispersão concentrada", ou seja, em boa medida os investimentos seguem em direção aos mesmos destinos (procurando economias de escala e escopo) que resultam em crescimento do comércio em menor proporção.

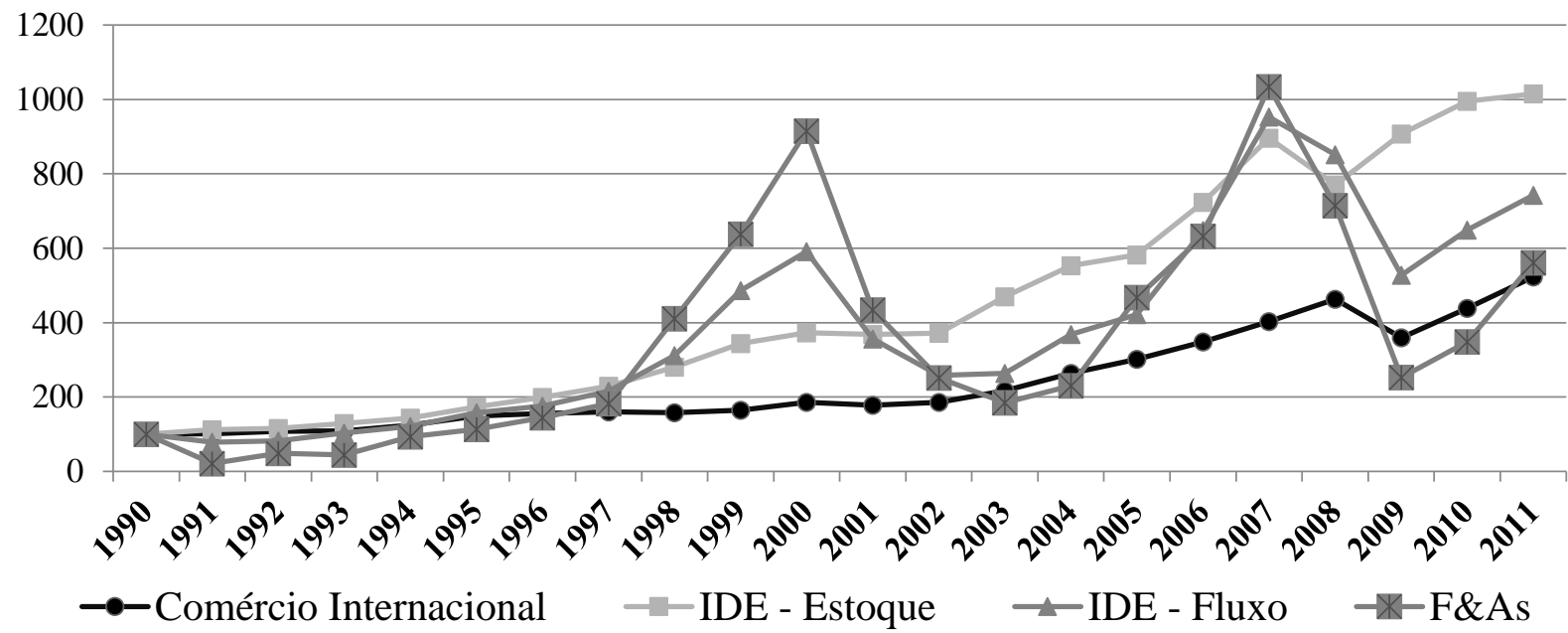

Gráfico 1 - Fluxo e Estoque mundial de IDE, F\&As e de Comércio Internacional (1990 = 100) Fonte: UnctadStat (2013). Elaboração própria.

É possível estabelecer as diferenças nos fluxos de IDE nas três últimas décadas. Durante a década de 1980, o IDE apresentou duas características principais (CHESNAIS, 1996; cap 2): i) concentração nos países desenvolvidos (na área da OCDE), principalmente mediante o investimento cruzado entre a "Tríade" (Estados Unidos, Japão e Europa); e ii) a supremacia das F\&As na participação do IDE. Nos períodos posteriores, ambas as características se mantêm em essência, mas há alterações importantes: as F\&A são intensificadas e os destinos do IDE são ampliados em direção a alguns países em desenvolvimento, assim como o comércio internacional (UNCTADSTAT, 2013).

Para Baldwin (2011), a partir da segunda metade da década de 1980, a maioria das nações industrializadas e parte das economias em desenvolvimento integrou-se às cadeias produtivas das empresas de média e alta tecnologia, principalmente oriundas dos EUA, Japão e Alemanha. A revolução tecnológica nas TICs proporcionou a redução dos custos de coordenação e incentivou a partição das cadeias de valor e a internacionalização de alguns dos seus elos, especialmente a manufatura. Nesse processo, as empresas dos países desenvolvidos transferiram segmentos dessas cadeias para países em desenvolvimento, combinando as tecnologias desenvolvidas "nas matrizes" 
com os baixos salários dos "países periféricos". "Este "empréstimo de tecnologia' pode revolucionar a produção da indústria de um país em desenvolvimento quase da noite para o dia" (BALDWIN, 2011;33).

Na década de 1990 e no início do século XXI os fluxos de IDE continuaram sendo primordialmente com origem e destinados aos $\mathrm{PD}$, mas a diferença na participação dos $\mathrm{PeD}$ vem sendo continuadamente reduzida. Se nos anos 1980 as economias desenvolvidas foram destino de $78 \%$ do IDE (e origem de 94\%), na década de 1990 e anos 2000 essa participação alterou para cerca de $72 \%(89 \%)$ e $61 \%$ (81\%), respectivamente. Além do expressivo aumento no volume de investimentos, houve uma paulatina desconcentração do IDE em direção aos países em desenvolvimento. Ademais, intensificam-se os fluxos no sentido contrário ao tradicional, ou seja, o IDE realizado pelos países em desenvolvimento vem ganhando dimensão: a participação do IDE com origem nos países em desenvolvimento mais que dobrou no mesmo período (UNCTADSTAT, 2013).

Nesse processo, o direcionamento dos investimentos é determinado sobretudo pelas estratégias das empresas. Dunning e Lundan (2008, cap 3) classificam o processo de internacionalização das empresas através do IDE em quatro diferentes objetivos: busca por recursos (naturais), busca (exploração) por mercados, busca por eficiência; busca de ativos estratégicos; busca por alianças estratégicas. Enquanto a busca por recursos e por mercados sustentaram as motivações básicas iniciais para o IDE, as demais estratégias -representam um aprofundamento do compromisso da empresa com o mercado estrangeiro e, possivelmente, uma inserção diferenciada na estrutura e nas funções corporativas e em maior autonomia da subsidiária (GOMES, 2006, cap 2). No contexto atual, de dispersão internacional e integração das atividades corporativas e dos fornecedores associados, as três últimas estratégias ganham relevância em detrimento das duas primeiras.

As transformações subjacentes aos fluxos de IDE (dispersão e controle de atividades, por um lado, integração e coordenação, por outro) motivaram o desenvolvimento do conceito de "cadeias globais de valor" (CGV). Segundo Gereffi et al. (2001) as CGV referem-se à distribuição e integração das atividades de produção de bens e serviços de forma global, ou seja, além das fronteiras nacionais. Nessa perspectiva, repartidas de acordo com as estratégias globais/regionais das empresas, as atividades de maior ou menor valor adicionado (funções de diferentes intensidades tecnológicas) são alocadas em diferentes países e determinam a magnitude e a direção dos fluxos (assimétricos) de comércio intrafirma. Os fornecedores e empresas terceirizadas em diferentes regiões completam as redes de comércio e de produção internacional associados.

As estruturas e composição da pauta de comércio e os países que participam das CGV podem ser determinados pela chamada governança dessas cadeias. Gereffi et al. $(2005 ; 84)$ elenca cinco tipos de governança das CGV: (1) Mercado: nos casos das transações de produtos padronizados, as interações podem ser transitórias, os custos de mudança para novos parceiros são baixos para ambas as partes; (2) Cadeias de valor modular: fazem produtos especializados para um cliente, que podem ser mais ou menos complexos, mas, para isso, desenvolveram capacidades próprias e de design (setor de eletrônicos; GAWER, 2009); (3) Redes de valor relacional: o conhecimento tácito e a necessidade de compartilhar ativos estabelecem interações complexas entre compradores e vendedores, o que muitas vezes cria dependência mútua e altos níveis de especificidade de ativos - a confiança e a reputação são fatores fundamentais nessas relações (setor automobilístico; GEREFFI et al., 2005); (4) Cadeias de valor cativas: apesar de produtos não padronizados, que requerem investimentos específicos, os fornecedores dependem diretamente de seus clientes (apenas um, em muitos casos), que se caracterizam pelo alto grau de monitoramento e controle - por exemplo. As cadeias de vestuário, controlado pelas grandes redes varejistas; (5) Hierarquia: caracterizada pela integração vertical, relação entre matriz e filial.

Os níveis de coordenação desses tipos de governança irão depender de três variáveis: i) a complexidade das transações das informações e conhecimentos necessários às especificações de produtos e processos; ii) a forma com que essas informações e conhecimentos podem ser codificados, ou seja, como podem ser transmitidos de forma eficiente e sem custos; iii) as capacidades dos 
fornecedores reais e potenciais em relação aos requisitos da transação. Essas variáveis dependem dos países onde as empresas estão ou pretendem atuar. Nestes casos, fatores externos às empresas ou questões estruturais (educação, institucional, ambiente de negócios, etc) também contribuem na participação mais ou menos qualificada do país nas CGV (GEREFFI et al., 2005; 98).

Independente da forma de gestão acima descrita, seja ela entre matriz-filial, fornecedorprodutor, fornecedor-vendedor (GEREFFI, 1994), as transações das CGV envolvem diferentes serviços. As atividades industriais e de serviços compõem de forma sistêmica essa integração global, mas se diferenciam pela capacidade de agregação de valor. A curva intitulada "Boca Sorridente" (OCDE, 2013; cap. 7), procura caracterizar as mudanças recentes na contribuição relativa das etapas da cadeia de valor em termos de valor adicionado. Se, por um lado, a parcela de valor adicionado pela manufatura (produção - etapa intermediária) vem sendo gradativamente reduzida, por outro, os elos pré-produção (P\&D, design, logística, etc) e pós-produção (marketing, logística e distribuição) têm aumentado a participação relativa na criação de valor-os elos iniciais e finais da cadeia se deslocam para cima e a parte central para baixo, similar ao movimento de uma boca ao esboçar um sorriso. Esse fenômeno é potencializado pelas inovações em processo, diferenciação de produtos e criação de novos modelos de negócios (OCDE, 2013; 217).

Em suma, essa analogia procura explicitar como nas últimas décadas a partilha da renda está sendo redistribuída entre as atividades econômicas, favorecendo certos serviços - pré e pós-produção - em detrimento da manufatura. Entretanto, é importante ressaltar que essa tipologia não é uma regra universal. Por exemplo, a indústria de vestuário na Itália apresenta alta competitividade na especialização em nichos de mercado baseada em fatores - inovação contínua, alta produtividade e qualidade - que permitem tais empresas a competir com outras de países com custos menores. Neste caso, a geração de valor depende da capacidade de fornecer produtos e serviços sofisticados e difíceis de imitar sem trabalho qualificado (OCDE, 2013; cap 7, 217).

A especialização das economias desenvolvidas em atividades de maior valor agregado reflete também os investimentos na formação de recursos humanos qualificados (OCDE, 2013; 218). Os investimentos em etapas intensivas em conhecimento têm aumentado de forma expressiva desde a década de 1980 impulsionados e facilitados pelo advento das tecnologias de informação e comunicação (TICs) e crescente dependência dos bens (particularmente na diferenciação de produtos) e processos industriais (automação e gestão) dessas tecnologias (especialmente daquelas soluções incorporadas nos softwares). Nesse processo, a produção de conhecimento pelas instituições de ensino e pesquisa, as relações entre universidade e empresas e, especialmente, o sistema nacional de inovação (LUNDVALL, 2007) é essencial para a geração, difusão e aplicação do conhecimento (ANTONELLI, 1998; 181).

Nesse contexto, as atividades de serviços ligadas ao desenvolvimento de produtos industriais aparecem como essenciais na estrutura e composição dos fluxos comerciais. Em primeiro lugar, por estabelecer a direção do investimento direto e, consequentemente, a geografia espacial da manufatura - em parte transferida para os países em desenvolvimento - e os fluxos comerciais ("visíveis") de bens. Em segundo lugar, por permitir a coordenação dessas cadeias pela governança e/ou pelo controle das funções densas em conhecimento técnico-científico (ativos estratégicos), que estão parcialmente refletidas nas transações internacionais ("invisível”) dos serviços. Em suma, as características básicas que sustentam a atual divisão internacional do trabalho.

Para Buckle et al. (1991; 53), o processo de internacionalização dos serviços é guiado por duas causas principais: a primeira, relacionada aos serviços incorporados aos bens físicos, ou seja, quando os serviços estão embarcados em um produto tangível (exemplo dos softwares); a segunda, quando a produção e o consumo de serviços podem ser separados, isto é, quando as empresas adquirem serviços especializados no exterior, como, por exemplo, serviços de consultoria jurídica, financeira, gestão empresarial, pesquisa, etc. LOW (2013), baseado pelo primeiro motivo acima, argumenta sobre o aumento da importância dos serviços nos fluxos comerciais e mostra os desafios para quantificar o valor dos serviços nos bens industriais. Tais dificuldades decorrem da natureza 
intangível, a heterogeneidade existente dentro dos diferentes segmentos e ausência de uma nomenclatura para os serviços.

A Organização para a Cooperação e Desenvolvimento Econômico (OCDE) e a OMC desenvolveram a base de dados Trade in Value-Added (TiVA), para quantificar o valor adicionado consumido na produção de bens e serviços. Para Arbache $(2015 ; 23)$ essas estatísticas de valor adicionado, "tem ensejado movimentos de revisão de acordos comerciais e introdução de novas formas de proteção em acordos bilaterais e regionais de comércio e investimentos". Para mensurar essas relações, Cernat e Kutlina-Dimitrova (2014) propõem reformas nas regras do GATS com a intenção de avaliar os serviços embutidos. Para os autores, essas mudanças são importantes para os policy maker estabelecerem regras comerciais mais adequadas à integração entre indústria de transformação e serviços.

Em resumo, a combinação das estratégias das empresas multinacionais, questões estruturais dos países (educação, institucional, ambiente de negócios, etc) e crescimento da importância do setor de serviços foram determinantes para as transformações e direcionamento (países), magnitude (valores) e pauta (aumento do setor de serviços) do comércio internacional. Para complementar essa análise as próximas seções procuram quantificar estas transformações.

\section{Interações no Comércio Internacional: Relações entre PD e PeD}

Esta seção avalia as relações comerciais dos quatro agregados econômicos (recursos naturais, indústria de transformação, construção e serviços) entre economias em diferentes estágios de desenvolvimento - países desenvolvidos (PD) e em desenvolvimento (PeD). A base de dados utilizada é a World Input-Output Database (WIOD) da Matriz Insumo-Produto mundial2 ${ }^{2}$ Essa matriz é construída por meio das Tabelas de Recursos e Usos e do Sistema de Contas Nacionais calculadas pelos institutos oficiais de estatística de cada país, além de informações de comércio obtidas no UN COMTRADE database ${ }^{3}$. Como as estatísticas para o ano de 2011 (último disponível) estão incompletas, este estudo adota os anos de 1995 e 2010 (dois extremos da série disponível) para a avaliação das mudanças ocorridas no período. Além disso, nesta análise foram considerados apenas os dados das relações comerciais que excluem da matriz de relações intersetoriais mundial (MIPm)os valores das transações internas de cada país, ou seja, são desconsiderados os fluxos nacionais.

A MIPm de comércio internacional foi condensada em países desenvolvidos (PD) e países em desenvolvimento $(\mathrm{PeD})^{4}$ e os setores agregados em recursos naturais, construção, serviços e indústria de transformação, formando uma matriz $(8 \times 8)$ de comércio internacional com as linhas representando as exportações e as colunas as importações. Assim, a matriz elaborada permite analisar as vendas (exportações) e compras (importações) de cada bloco/agregado. É importante ressaltar que os dados deste estudo não contabilizam os serviços embutidos em um produto tangível, mas apenas os serviços que podem ser separados como tal, por exemplo, serviços de consultoria jurídica, financeira, gestão empresarial, pesquisa, etc. O recorte metodológico desta seção permite avaliar de forma agregada: i) a participação dos PD e PeD no comércio internacional; ii) a decomposição desses fluxos segundo os agregados recursos naturais, construção, serviços e indústria de transformação nos dois grupos de países, e; iii) avaliar a interação entre os grupos de agregados. As tabelas 1 e 2 (soma das participações das exportações por bloco/agregado) mostram os resultados após os procedimentos descritos acima.

\footnotetext{
${ }^{2}$ Atualmente, o banco de dados contempla 40 países (27 países da União Europeia e 13 de outras regiões), representando aproximadamente $85 \%$ da produção mundial, mas também são consideradas as interações destes países com o resto do mundo (disponibilizadas na matriz mundial).

${ }^{3}$ Metodologia em Timmer (2012), disponível em http://www.wiod.org.

${ }^{4}$ De acordo com a classificação da UNCTADstat, 2013. Ademais, o item que representa o resto do mundo foi agregado nos países em desenvolvimento $(\mathrm{PeD})$.
} 


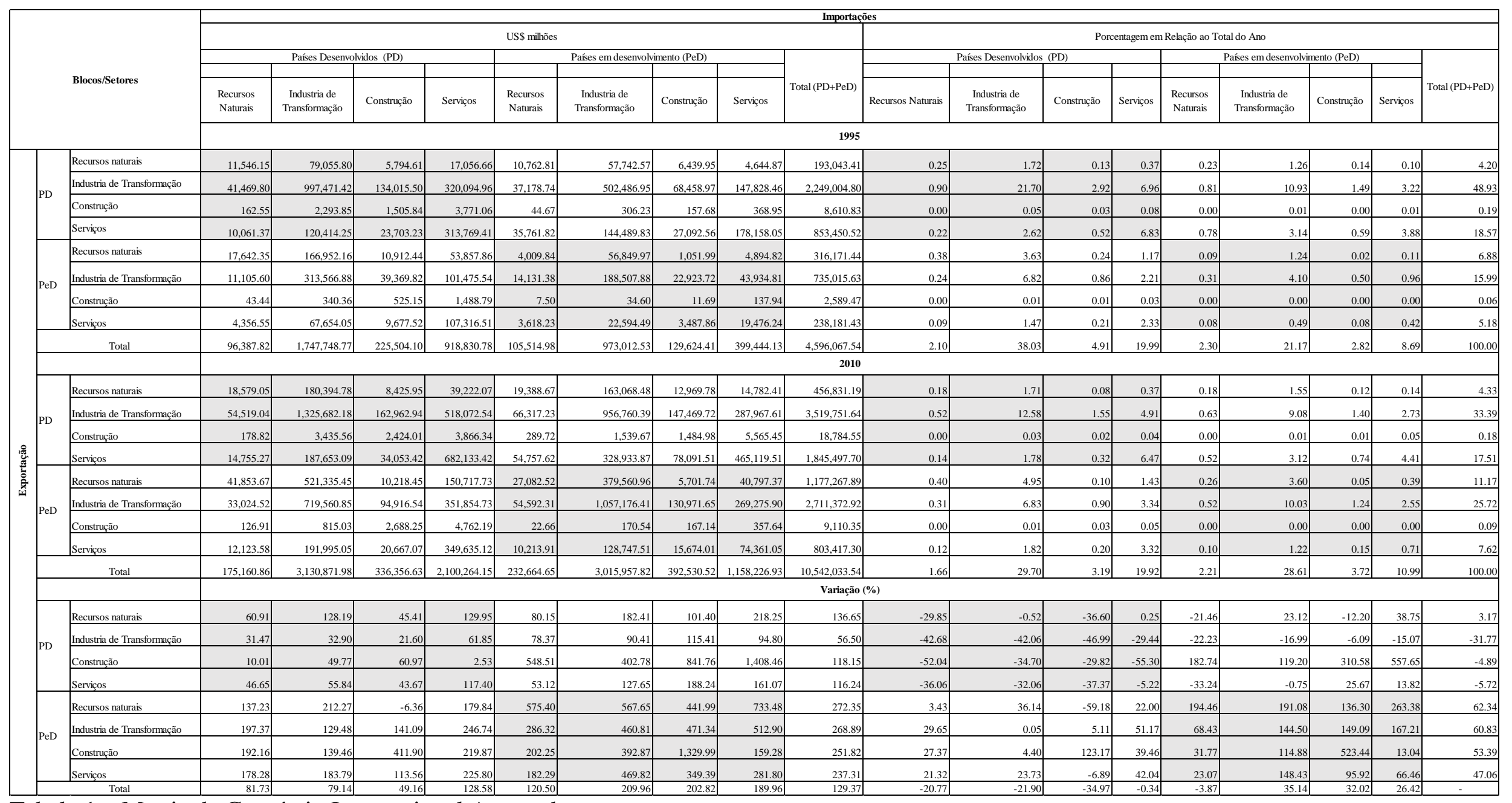

Tabela 1 - Matriz de Comércio Internacional Agregada

Fonte: World Input-Output Database (WIOD). Elaboração própria.

Notas: (1) Países desenvolvidos (PD) e em desenvolvimento (PeD) contemplam todos os países disponíveis na WIOD. (2) Valores deflacionados pelo OCDEindex. 
Acompanhando a tendência do IDE apontada na seção anterior, a Tabela 1 mostra a desconcentração do comércio internacional: entre 1995 e 2010 as exportações dos PeD triplicaram (de cerca de US\$ 1,6 trilhão para US\$ 4,8 trilhões; crescimento de 198\%) e a dos PD duplicaram (de US\$ 3 trilhões para US\$ 5,7 trilhões; aumento de 92\%). Em outros termos, a participação relativa dos PD nas exportações mundiais no período diminuiu 10 pontos percentuais (parcela absorvida pelos PeD), mas os países desse bloco mantêm o domínio desses fluxos (55\%). Ressalte-se que essas mudanças ocorreram ao mesmo tempo em que o comércio internacional cresceu $130 \%$.

\begin{tabular}{|c|c|c|c|c|c|c|c|}
\hline Exportações de & $\begin{array}{l}\text { PD para } \\
\text { PeD (1) }\end{array}$ & $\begin{array}{c}\text { PD para } \\
\text { PD (2) }\end{array}$ & $\begin{array}{c}\text { PD para PD + } \\
\text { PeD }(1+2)\end{array}$ & $\begin{array}{l}\text { PeD para } \\
\text { PeD (3) }\end{array}$ & $\begin{array}{c}\text { PeD para } \\
\text { PD (4) }\end{array}$ & $\begin{array}{l}\text { PeD para PD } \\
+\operatorname{PeD}(3+4)\end{array}$ & $\begin{array}{c}\text { Total } \\
(1+2+3+4)\end{array}$ \\
\hline \multicolumn{8}{|c|}{1995} \\
\hline Recursos Naturais & 1.73 & 2.47 & 4.20 & 1.45 & 5.43 & 6.88 & 11.08 \\
\hline Industria de Transformação & 16.45 & 32.49 & 48.93 & 5.86 & 10.13 & 15.99 & 64.93 \\
\hline Construção & 0.02 & 0.17 & 0.19 & 0.00 & 0.05 & 0.06 & 0.24 \\
\hline Serviços & 8.39 & 10.18 & 18.57 & 1.07 & 4.11 & 5.18 & 23.75 \\
\hline Total & 26.59 & 45.30 & 71.89 & 8.39 & 19.72 & 28.11 & 100.00 \\
\hline \multicolumn{8}{|c|}{2010} \\
\hline Recursos Naturais & 1.99 & 2.34 & 4.33 & 4.30 & 6.87 & 11.17 & 15.50 \\
\hline Industria de Transformação & 13.84 & 19.55 & 33.39 & 14.34 & 11.38 & 25.72 & 59.11 \\
\hline Construção & 0.08 & 0.09 & 0.18 & 0.01 & 0.08 & 0.09 & 0.26 \\
\hline Serviços & 8.79 & 8.71 & 17.51 & 2.17 & 5.45 & 7.62 & 25.13 \\
\hline Total & 24.71 & 30.70 & 55.41 & 20.82 & 23.77 & 44.59 & 100.00 \\
\hline
\end{tabular}

Tabela 2 - Participações das exportações por bloco/agregado (linhas da Tabela 1)

Fonte: World Input-Output Database (WIOD). Elaboração própria.

Notas: (1) Países desenvolvidos (PD) e em desenvolvimento (PeD) contemplam todos os países disponíveis na WIOD.

Outra característica marcante do processo de desconcentração foi o crescimento da participação do comércio entre os $\mathrm{PeD}$ (de 8,4\% em 1995 para 20,8\% em 2010), uma variação bastante expressiva se comparada com a desse bloco em direção aos PD $(19,7 \%$ e $23,7 \%$, respectivamente). Compensatoriamente, as transações entre os PD foram reduzidas significativamente (de 45,3\% para 30,7\%), enquanto as relações entre os países desenvolvidos e em desenvolvimento permaneceram praticamente constantes (ao redor de 25\%). Em suma, parte do aumento das vendas internacionais se deslocou do sentido "norte-norte" para a direção "sul-sul" e, em menor proporção, para "sul-norte". Esta, talvez, seja uma síntese das transformações recentes nas relações internacionais: o crescimento do comércio e oferta mundial sustentados pelos PeD.

Entre os grupos de setores representados na matriz, destaque para o aumento da participação dos setores de recursos naturais oriundos dos $\mathrm{PeD}$, especialmente impulsionados pela elevação dos preços das commodities e crescimento da demanda chinesa - a participação do bloco no total das exportações desses bens cresceu de 6,9\% em 1995 para 11,2\% em 2010. Isoladamente este agregado colaborou para o aumento da relação entre os PeD (1,4\% para 4,3\%).

Entretanto, o principal grupo responsável pelas mudanças apontadas acima foi a indústria de transformação (5,9\% para 14,4\%), aspecto atrelado principalmente ao crescimento chinês nas últimas décadas (avaliado nas próximas seções). Ao mesmo tempo, houve uma elevada queda na representação das exportações industriais entre os PD (32,5\% para 19,5\%). No conjunto, esses resultados refletem o deslocamento espacial da manufatura.

As principais mudanças nas exportações mundiais do período ocorrem na indústria de transformação em particular, o crescimento de $77 \%$ da participação dos $\mathrm{PeD}$. Se a proporção do agregado nos PD em relação ao total das exportações declinou no período (de 49\% para 33\%; última 
coluna da Tabela 1), a parcela dos PeD aumentou (de 16\% para 26\%). Adicionalmente, a Indústria de Transformação continua detendo os mais elevados níveis de participação nas exportações (65\% para 59\%; vide cruzamentos dos totais na Tabela1) e importações $(59,2$ para 58,3), enquanto os Serviços conheceram um pequeno aumento nas exportações $(23,7 \%$ para $25,1 \%)$ e importações $(28,7 \%$ para $31 \%)$. Essa última variação decorre do crescimento das exportações $(5,18$ para 7,62$)$ e importações $(8,7 \%$ para $11 \%)$ dos $\mathrm{PeD}$, principalmente pelo aumento das relações entre os países do bloco - exportações $(1,07 \%$ para $2,17 \%)$ e importações $(1,49 \%$ para $2,55 \%)$. Em suma, essas estatísticas indicam que o deslocamento espacial da manufatura foi acompanhado pelo aumento do fluxo de serviços.

Por fim, as interações entre indústria e serviços tiveram um pequeno aumento da participação do consumo de serviços $(7,7 \%$ para $7,9 \%)$, proporção similar na relação inversa, serviço consumindo da indústria (13,3\% para 13,5\%). Nessas interações os PeD respondem pelas maiores mudanças: se as exportações de serviços para indústria cresceram de $2 \%$ para 3\% do total, 1,8\% (2010) dessa participação foi com os PD.

Em síntese, apesar de uma redução em relação ao total das exportações, a participação dos fluxos relativos às atividades industriais se mantém como a mais relevante no comércio internacional (cerca de 60\%). Ademais, os resultados desta seção corroboram a desconcentração do comércio mundial com o aumento da presença dos PeD, especialmente como fornecedores de bens industriais para o próprio bloco, mas incorporando também, em menor dimensão, alguns serviços. Essas relações parecem refletir o adensamento dos vínculos entre os $\mathrm{PeD}$. A próxima seção procura detalhar melhor os países participantes nesse processo.

\section{Metodologia de Redes Aplicada sobre as Matrizes de Comércio Internacional}

Esta seção busca complementar a descrição anterior sobre as transformações nas relações comerciais em países em diferentes estágios de desenvolvimento. A avaliação foi realizada para as doze maiores economias do mundo (segundo o PIB de 2010: Alemanha, Brasil, China, Coreia, EUA, França, Índia, Itália, Japão, México, Reino Unido e Rússia), para ressaltar por meio dos indicadores propostos as diferenças entre os países desenvolvidos (PD) e países em desenvolvimento (PeD) nos anos de 1995 e 2010. Ademais, em função do objetivo deste trabalho, é dado especial destaque para as interações entre a indústria e os serviços.

A partir dos dados da World Input-Output Database (WIOD) foi construída uma Matriz de Comércio Internacional que inclui, além dos países listados acima, "outros países desenvolvidos Outros PD" - e "outros países em desenvolvimento - Outros PeD" de comércio. Os valores das exportações e importações para cada um desses países foram agregados em recursos naturais, construção, serviços e indústria de transformação. Dessa forma, a economia de cada país (incluindo os outros PD e PeD totalizam 14 países/ blocos) foi dividida em quatro agregados originando uma Matriz de Comércio Internacional (56x56) para cada um dos anos de 1995 e 2010.

Para a Análise de Redes foram considerados apenas as ligações (fluxos) superiores a 0,02\% do total em cada ano, que representam $90 \%$ dos valores do comércio mundial ${ }^{7}$. Este recorte metodológico mantém nas matrizes obtidas as relações comerciais mais expressivas, eliminando

\footnotetext{
5 Austrália, Áustria, Bélgica, Bulgária, Canadá, Chipre, República Checa, Dinamarca, Espanha, Estônia, Finlândia, Grécia, Hungria, Irlanda, Lituânia, Luxemburgo, Letônia, Malta, Países Baixos, Polônia, Portugal, Romênia, República Eslovaca, Eslovênia, Suécia.

${ }^{6} \mathrm{O}$ item que representa o resto do mundo foi agregado nos Outros países em desenvolvimento (Outros PeD). Além dos países: Indonésia, Peru e Taiwan.
}

${ }^{7}$ Os fluxos desconsiderados totalizaram US\$ 919,21 milhões em 1995 e US\$ 2.108,40 milhões em 2010. 
fluxos pouco significativos ou eventuais. Ademais, as comparações das redes entre os dois anos permitem apenas avaliar as mudanças nas proporções e direcionamentos dos fluxos entre países ${ }^{8}$.

\subsection{Mudanças nos Fluxos dos Blocos Econômicos}

A análise pelo método de redes fornece dois indicadores básicos: i) número de linhas ou de ligações da rede - elos entre nós (setores); e ii) densidade da rede ou relação entre elos reais e os possíveis; densidade $=m /(n(n-1))$, onde $n$ é o número de nós e $m$ é o número de linhas (GOYAL, 2007) ${ }^{9}$. Assim, a densidade da rede varia no intervalo $[0,1]$; se a densidade é alta (próxima de 1), maior o número de ligações ou de relacionamentos e conexões entre os diferentes setores (SAVIOTTI, 2009). Estes indicadores complementam o exame anterior sobre as mudanças nos fluxos de comércio internacional entre os agregados industriais e entre os países.

A Tabela 3 mostra os resultados da densidade de rede nos dois anos analisados: 1995 e 2010. A densidade total foi desagregada em quatro densidades "parciais": Densidade Industrial (DI) que mensura apenas relações entre o setor industrial nos diferentes países; Densidade dos Serviços (DS) para determinar os elos das atividades de serviços; Densidade entre Indústria x Serviços (DIS) para medir os vínculos dessas duas atividades, e; Densidade Recursos Naturais e Construção (DRCT) que sintetiza (i) as interações entre eles e (ii) entre estes dois agregados e os demais (Indústria e Serviços) ${ }^{10}$. Adicionalmente, essas densidades parciais foram calculadas para as relações dentro e entre os dois blocos de países (PeD com PD).

Assim, a densidade total pode ser denotada por:

$$
\begin{gathered}
\text { Densidade total }(\mathrm{DT})=\mathrm{DIT}+\mathrm{DST}+\mathrm{DIST}+\mathrm{DRC} \\
\text { DIT }=(\mathrm{DI}-\mathrm{PeD})+(\mathrm{DI}-\mathrm{PD})+(\mathrm{DI}-\mathrm{PeD}+\mathrm{PD}) \\
\text { DST }=(\mathrm{DS}-\mathrm{PeD})+(\mathrm{DS}-\mathrm{PD})+(\mathrm{DS}-\mathrm{PeD}+\mathrm{PD}) \\
\text { DIST }=(\mathrm{DIS}-\mathrm{PeD})+(\mathrm{DIS}-\mathrm{PD})+(\mathrm{DIS}-\mathrm{PeD}+\mathrm{PD})
\end{gathered}
$$

\footnotetext{
${ }^{8}$ É importante ressaltar que na análise aqui utilizada não é possível uma análise do saldo do balanço comercial, pois as exportações são referentes aos produtos relacionados aos setores exportadores, mas as importações estão vinculadas ao setor demandante de certo bem, não sendo necessariamente do mesmo setor.

${ }^{9}$ Como este estudo trabalha com um número fixo de setores (nós), uma mudança na densidade decorre diretamente de variações nas relações intersetoriais (linhas).

${ }^{10}$ Considerando que este estudo prioriza as relações da indústria e serviços, aqui os agregados recursos naturais e construção são tratados como um único e não priorizados.
} 


\begin{tabular}{|c|c|c|c|c|c|c|}
\hline & \multicolumn{2}{|c|}{1995} & \multicolumn{2}{|c|}{2010} & \multicolumn{2}{|c|}{ Variação entre os Anos (\%) } \\
\hline & $(0-1)$ & $\%$ & $(0-1)$ & $\%$ & $(0-1)$ & $\%$ \\
\hline Densidade Total (DT) & 0.181 & 100 & 0.189 & 100 & 4.50 & - \\
\hline Densidade Industrial total (DIT) & 0.041 & 22.8 & 0.041 & 21.9 & 0.00 & -4.30 \\
\hline Densidade dos Serviços total (DST) & 0.027 & 14.7 & 0.027 & 14.1 & 0.00 & -4.30 \\
\hline Densidade Indústria x Serviços total (DIST) & 0.048 & 26.4 & 0.053 & 27.9 & 10.20 & 5.46 \\
\hline Densidade Recursos Naturais e Construção (DRC) & 0.065 & 36.0 & 0.068 & 36.1 & 5.00 & 0.48 \\
\hline \multicolumn{7}{|l|}{ Apenas a Densidade entre PeDs } \\
\hline (1) Densidade Industrial (DI-PeDs) & 0.006 & 3.2 & 0.008 & 4.5 & 44.44 & 38.23 \\
\hline (2) Densidade dos Serviços (DS-PeDs) & 0.003 & 1.4 & 0.002 & 1.2 & -12.50 & -16.27 \\
\hline (3) Densidade Indústria x Serviços (DIS-PeDs) & 0.006 & 3.2 & 0.010 & 5.2 & 66.67 & 59.50 \\
\hline Total $(1+2+3)$ & 0.014 & 7.9 & 0.020 & 10.8 & 43.18 & 37.02 \\
\hline \multicolumn{7}{|l|}{ Apenas a Densidade entre PDs } \\
\hline (4) Densidade Industrial (DI-PDs) & 0.014 & 7.6 & 0.013 & 6.7 & -7.14 & -11.14 \\
\hline (5) Densidade dos Serviços (DS-PDs) & 0.012 & 6.8 & 0.009 & 4.6 & -28.95 & -32.00 \\
\hline (6) Densidade Indústria x Serviços (DIS-PDs) & 0.021 & 11.9 & 0.017 & 9.1 & -19.70 & -23.15 \\
\hline Total $(4+5+6)$ & 0.047 & 26.3 & 0.039 & 20.5 & -18.49 & -22.00 \\
\hline \multicolumn{7}{|l|}{ Apenas a Densidade entre PeDs e PDs } \\
\hline (7) Densidade Industrial (DI-PeDsPDs) & 0.022 & 12.1 & 0.020 & 10.7 & -7.46 & -11.44 \\
\hline (8) Densidade dos Serviços (DS-PeDsPDs) & 0.012 & 6.5 & 0.016 & 8.3 & 33.33 & 27.60 \\
\hline (9) Densidade Indústria x Serviços (DIS-PeDsPDs) & 0.020 & 11.3 & 0.026 & 13.6 & 25.40 & 20.00 \\
\hline Total $(7+8+9)$ & 0.054 & 29.9 & 0.061 & 32.5 & 13.86 & 8.96 \\
\hline
\end{tabular}

Tabela 3 - Características Gerais das Densidades de Rede com os Países Selecionados

Fonte: World Input-Output Database (WIOD). Elaborado pelo autor a partir do software Pajek.

Notas: (1) Países desenvolvidos (PDs) e em desenvolvimento (PeDs) contemplam os países da amostra e os países agregados em Outros PeDs e Outros PDs.

Diferindo da anterior, esta seção mensura os números de elos, ou seja, avalia a variação da dispersão dos fluxos de comércio entre os diferentes países. Os resultados apresentados na Tabela 3 permitem observar três tendências. A primeira se refere às proporções as densidades totais tiveram pouca ou nenhuma variação, indicando reduzidas mudanças no número total de elos de comércio entre 1995 e 2010, especialmente se considerado o crescimento nos valores desses fluxos - vide item anterior. A despeito dessa variação quase nula entre os dois anos, duas ressalvas são necessárias: as relações dos agregados indústria e serviços $(10,2 \%)$ e recursos naturais e construção $(5 \%)$ respondem pela variação da densidade total. Em particular, a primeira é mais relevante para este estudo não só por ser maior, mas por expressar melhor as mudanças estruturais do cenário internacional.

Em suma, aumento do comércio internacional não pode ser caracterizada como uma “expansão virtuosa”, ou seja, acompanhado pela criação de novos vínculos intersetoriais (novos atores e/ou atividades) onde inexistiam. Ao contrário, em termos gerais as mudanças ocorridas parecem descrever a um "jogo de soma zero" - a criação de um novo ele representa a eliminação de um antigo, isto é, transferência de origem e/ou destino dos elos estabelecidos. Por outro lado, o crescimento da densidade da DIST indica que as mudanças na composição dos fluxos comerciais foram mais intensas entre indústria de transformação e serviços.

Entretanto, as alterações na densidade total não revelam as reais das transformações nos vínculos inter e intrablocos e agregados setoriais como fazem as densidades parciais. Se o número de elos e a participação relativa dos fluxos de comércio entre os PD foram reduzidos em todos os agregados (desconcentração e/ou mudanças nos fluxos), ocorreu o inverso para os PeD. Essa é a segunda tendência que pode ser extraída da Tabela 3, ou seja, relacionada à mudança de direção das relações de comércio: crescimento do número de elos entre os PeD e diminuição entre os PD. Nos vínculos entre os $\mathrm{PeD}$, destaque, novamente, para o aumento das relações entre indústria de transformação e serviços (variação DIS-PeD de $69 \%$ e 59\%), seguido pelas relações industriais (variação de DI-PeD de $44 \%$ e 38,2\%). 
Entre os PD, a queda é generalizada em todas as densidades "parciais", confirmando a desconcentração desse bloco em termos de fluxos de comércio internacional. Ressalte-se que esta tendência é mais acentuada nos indicadores relativos aos serviços, tanto no número de elos como nas participações relativas (variação DS-PDs de $-29 \%$ e $-32 \%$ e DIS-PDs de $-19 \%$ e $-23 \%$, respectivamente). Se esse comentário for associado aos anteriores elaborados para os $\mathrm{PeD}$, intui-se que além dos deslocamentos dos fluxos de bens, parte do comércio internacional de serviços também parece ter sido transferida para os PeD. Nesse sentido, o deslocamento da manufatura parece ter carregado em seu bojo alguns serviços.

A terceira tendência, que complementa as duas anteriores, parece refletir a nova divisão internacional do trabalho. A participação relativa das relações entre indústria de transformação e serviços cresceu (DIS-PeDPD com parcela de 11,3\% em 1995 e 13,6\% em 2010), como reflexo do aumento da densidade total. Esse aspecto denota duas transformações combinadas: a maior interação entre PeD e PD juntamente com o aumento das relações entre os agregados indústria e serviços. Além disso, se a densidade parcial do serviços diminui intra blocos (-29\% nos PD e $-13 \%$ nos PeD), ela cresceu cerca de $33 \%$ interblocos.

Ressalte-se que a densidade parcial intraindustrial do PD foi reduzida em cerca de $11 \%$. Se analisada em conjunto com as relações entre os PeD (crescimento de 44\%), temos que os fluxos comerciais desse agregado concentrou-se nesse último bloco em detrimento do primeiro. Em suma, mais uma evidência de dispersão - transferência dos países desenvolvidos - concentrada - nos países em desenvolvimento - da manufatura. A próxima seção busca ponderar e comparar a participação da Indústria de Transformação e Serviços nesse processo para os países selecionados.

\subsection{Análise de Rede: Parceiras Comerciais e Participação Relativa}

Os indicadores utilizados nesta seção mensuram o número de relações diretas dos diferentes setores de cada país. Para isso, separamos os elos em exportação e importação e, adicionalmente, utilizamos a ponderação dos valores das ligações totais. Entre as principais vantagens do método está a representação gráfica dessas relações: o tamanho da "bolha" representa a proporção do país/setor no comércio internacional e o número de ligações (valores em parêntese ao lado da nomenclatura) para as exportações e importações - vide figura 1. Essas redes permitem visualizar: i) "transparência" das redes dadas pelas linhas ("mais claro", menos linhas, menos fluxos comerciais); ii) o número de relações ou parceiros comerciais de cada país.

Com relação à "transparência", o principal aspecto é que as redes das figuras abaixo apresentam maior número de linhas em 1995 (mais escura) do lado direito para ambos os fluxos. Isso significa que o comércio neste ano estava mais concentrado entre as economias desenvolvidas. Essa percepção difere nas redes de 2010 devido à desconcentração do comércio internacional e maior presença de países em desenvolvimento (lado esquerdo) nas redes - fenômeno enfatizado nas seções anteriores. 

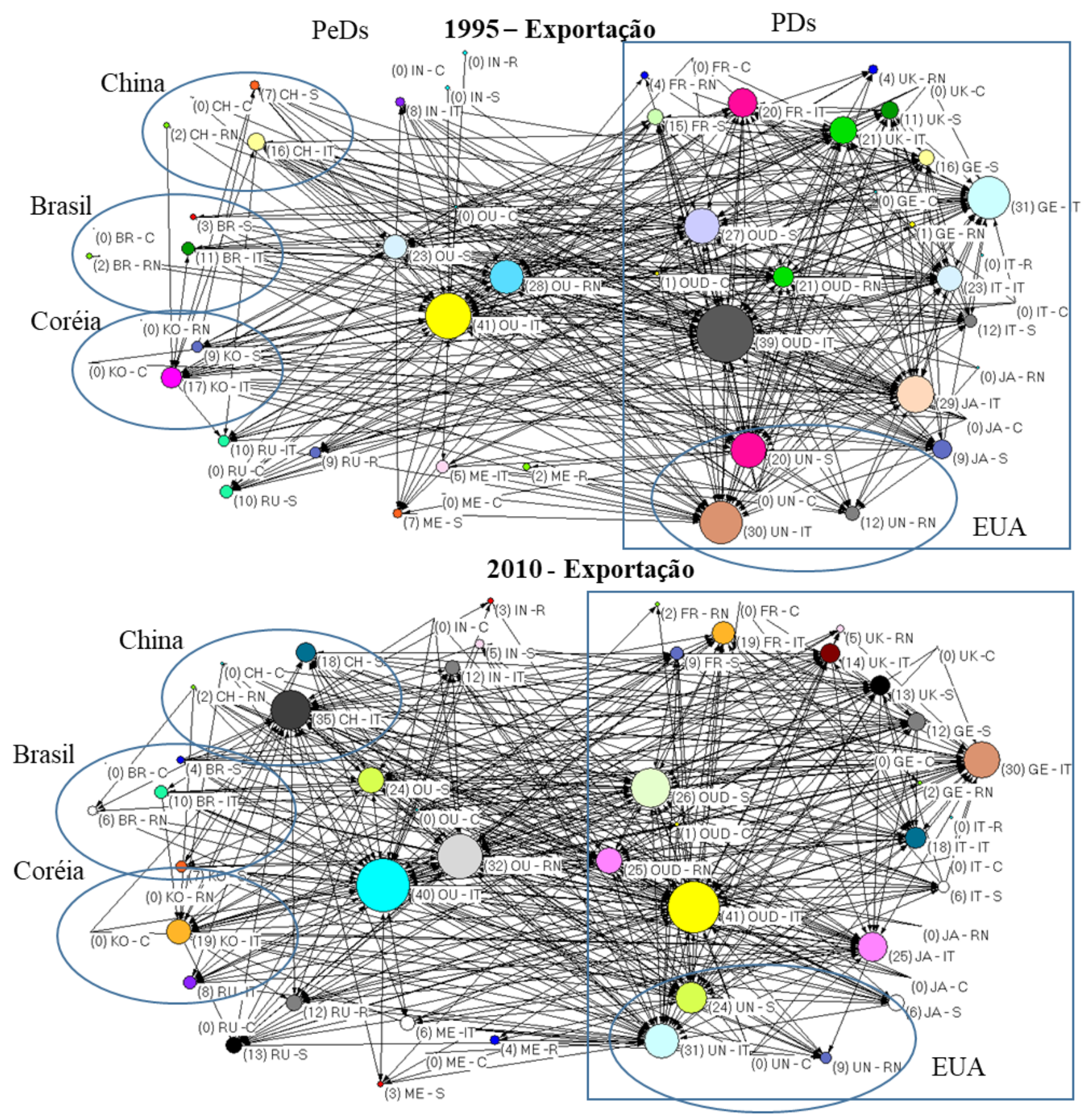

Figura 1.1 - Redes do Comércio Internacional em 1995 e 2010 (tamanho das bolhas ponderadas pelo total de cada ano)

Fonte: Elaboração própria a partir de dados da WIOD e software Pajek.

Países: CH - China; IN - Índia; BR - Brasil; KO - Coreia; RU - Rússia; ME - México; OU - Outros PeDs; FR - França; UK - Reino Unido; OUD - Outros PDs; UN - Estados Unidos; GE - Alemanha; JA - Japão; IT - Itália. Setores: RN- Recursos Naturais; C- Construção; S- Serviços e IT- Indústria de Transformação. Notas: (1) valores em parêntese ao lado da nomenclatura mostram o número de ligações de cada setor na rede; (2). Os tamanhos das bolhas representam a participação nas Exportações e Importações no ano. 

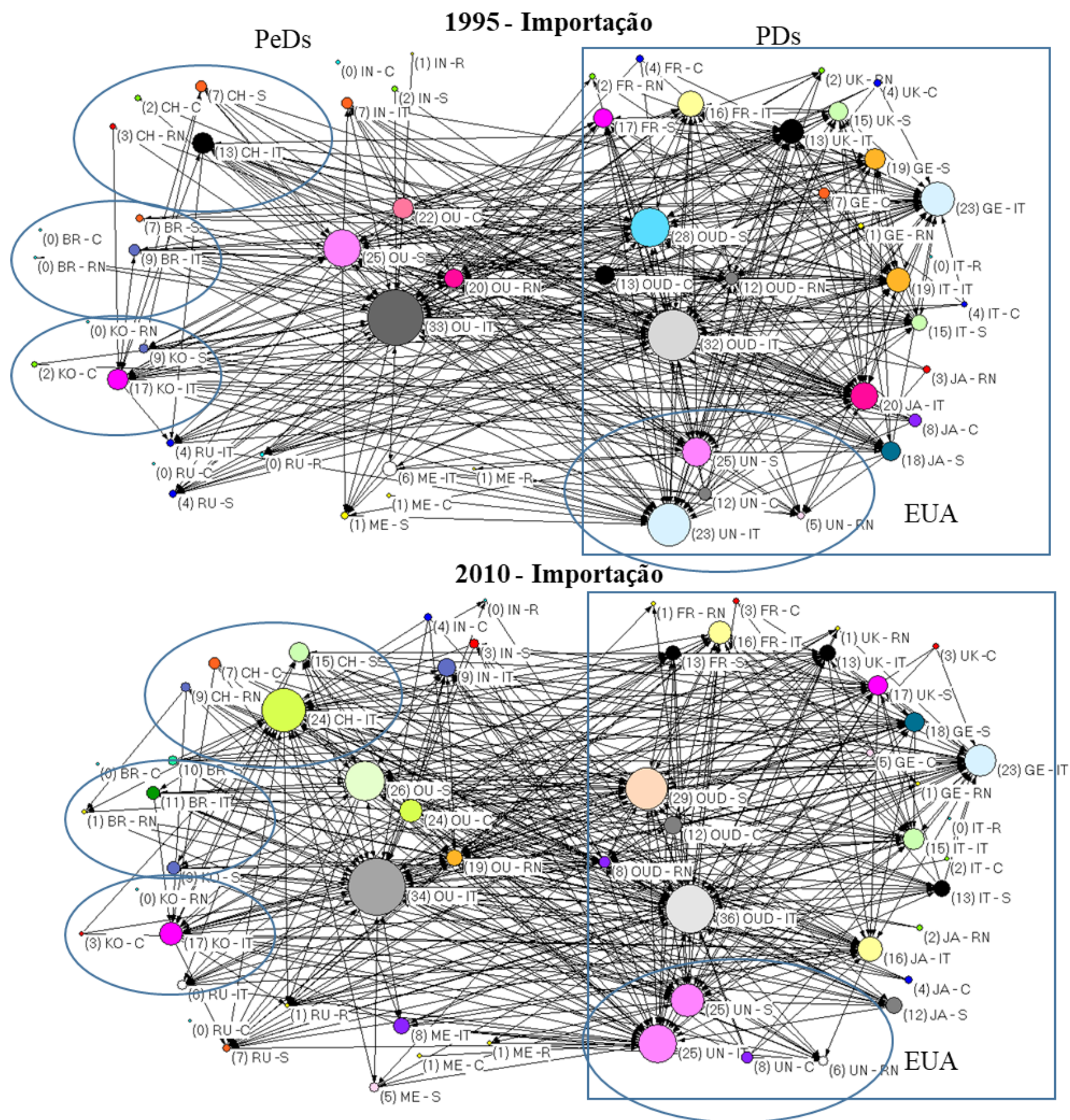

Figura 1.2 - Redes do Comércio Internacional em 1995 e 2010 (tamanho das bolhas ponderadas pelo total de cada ano)

Fonte: Elaboração própria a partir de dados da WIOD e software Pajek.

Países: CH - China; IN - Índia; BR - Brasil; KO - Coreia; RU - Rússia; ME - México; OU - Outros PeDs; FR - França; UK - Reino Unido; OUD - Outros PDs; UN - Estados Unidos; GE - Alemanha; JA - Japão; IT - Itália. Setores: RN- Recursos Naturais; C- Construção; S- Serviços e IT- Indústria de Transformação. Notas: (1) valores em parêntese ao lado da nomenclatura mostram o número de ligações de cada setor na rede; (2). Os tamanhos das bolhas representam a participação nas Exportações e Importações no ano. 
A Tabela 4 destaca os setores de Serviços (Se) e Indústria de Transformação (IT) nos países selecionados ${ }^{11}$.

As exportações da China ( $\mathrm{CH}$ no gráfico) são o maior destaque do período, razão principal das transformações entre os $\mathrm{PeD}$. O grande aumento da participação chinesa nas exportações mundiais é devido não apenas pelo crescimento da Indústria de Transformação, mas também dos Serviços - o número de elos com países/setores dos Serviços foi de 7 em 1995 para 18 em 2010 e da indústria de 16 para 35 elos. Em outras palavras, em 2010, além da liderança nas exportações mundiais de bens industriais, a China (1,68\%) é superada apenas pelos EUA $(4,5 \%)$ e similar ao Reino Unido (1,7\%) nas exportações de serviços.

No que tange às importações, a China aparece também como grande comprador mundial, mantendo a mesma relação hierárquica das vendas com os EUA: a Indústria de Transformação puxou o processo de transformação (PIMP da IT com Variação de 336,1\%). Para Rodrik (2007) o sucesso da China aconteceu devido um conjunto de políticas industriais acompanhadas de uma abertura econômica muito gradual em mais de uma década. Além disso, a China passou de uma montadora de componente para, cada vez mais, uma produção integrada de alta produtividade, com capacidade de exportação de produtos sofisticados (RODRIK, 2007; 22).

A Coreia (KO no gráfico) é um PeD que jáhavia alcançado expressão na área indústrial e intensificou a quantidade de ligações e a participação nas exportações industriais (Variação de 11,8\% e $37,2 \%$ da LEXP e PEXP, respectivamente). O país manteve em níveis elevados os elos das importações e aumentou a participação (PIMP) nas importações totais nos dois grupos setoriais, especialmente serviços (52\%). Em suma, a intensificação dos vínculos via exportação parece ter elevado a demanda por serviços, ou seja, um caso de fortalecimento da estrutura industrial. Baldwin (2011) corrobora este resultado ao descrever que o sucesso coreano é resultado de um conjunto de políticas industriais aplicadas desde a década de 1960. O autor destaca que o país mantém uma produção extremamente integrada nas CGV - por exemplo, ao mesmo tempo em que detém elevados índices de exportação de motores de automóveisé grande importadora de ignição utilizada na fabricação destes motores, (BALDWIN, 2011; 33).

Os resultados da China e Coreia expressam certa simetria no crescimento industrial e de serviços, também nas exportações e importações. Em ambos os casos, a relação no comércio internacional da Indústria de Transformação com os Serviços intensificou. Se para a China houve uma extensa integração aos fluxos mundiais (número de elos comerciais cresceu em ambos os fluxos entre 1995 e 2010), os vínculos relativos às compras industriais coreanas ficaram estagnados. Adicionalmente, as exportações de serviços para a indústria (SEXPI) mais que dobraram na China e a importação de serviços pela indústria (SIMP) aumentou em ambos os países no período. Este parece ser mais um indício de que (i) a Coreia baseia o seu desempenho nas atividades industriais, (ii) as exportações de bens crescentemente "embarcam" conteúdo de serviços e (iii) parte delas suprida pelas importações de serviços.

\footnotetext{
${ }^{11}$ Em razão do recorte metodológico, o setor exportador/importador (Serviços, Recursos Naturais, Construção e Indústria de Transformação) de um país pode ter até 4 elos com outro país, totalizando o máximo de 52 ligações.
} 


\begin{tabular}{|c|c|c|c|c|c|c|c|c|c|c|c|c|c|c|c|c|c|c|c|c|c|c|c|c|}
\hline & \multicolumn{6}{|c|}{ Número de Ligações - Exportação- LEXP } & \multicolumn{6}{|c|}{ Participação nas Exportaç̃os - PEXP } & \multicolumn{6}{|c|}{ IT Exporta para Serviços - IEXPS } & \multicolumn{6}{|c|}{ Serviços Exporta para IT - SEXPI } \\
\hline & \multicolumn{2}{|c|}{1995} & \multicolumn{2}{|c|}{2010} & \multicolumn{2}{|c|}{ Variação (\%) } & \multicolumn{2}{|c|}{1995} & \multicolumn{2}{|c|}{2010} & \multicolumn{2}{|c|}{ Variação (\%) } & \multicolumn{3}{|c|}{ Participação nas Exportações } & \multicolumn{3}{|c|}{ Número de Ligações } & \multicolumn{3}{|c|}{ Participação nas Exportações } & \multicolumn{3}{|c|}{ Número de Ligações } \\
\hline & $\mathrm{Se}$ & IT & $\mathrm{Se}$ & IT & Se & IT & Se & IT & Se & IT & Se & IT & 1995 & 2010 & \begin{tabular}{|l|}
$\operatorname{Var}(\%)$ \\
\end{tabular} & 1995 & 2010 & $\operatorname{Var}(\%)$ & 1995 & 2010 & $\operatorname{Var}(\%)$ & 1995 & 2010 & $\operatorname{Var}(\%)$ \\
\hline Brasil & 3 & 11 & 4 & 10 & 33.3 & -9.1 & 0.10 & 0.70 & 0.21 & 0.67 & 102.9 & -5.1 & 0.12 & 0.14 & 17.05 & & & -33.33 & 0.03 & 0.09 & 203.64 & & 2 & 100.00 \\
\hline China & 7 & 16 & 18 & 35 & 157.1 & 118.8 & 0.30 & 1.38 & 1.68 & 6.74 & 460.1 & 388.1 & 0.24 & 1.72 & 623.67 & 4 & 13 & 75.00 & 0.15 & 0.48 & \begin{tabular}{l|l}
229.99 \\
2
\end{tabular} & 2 & 7 & 250.00 \\
\hline Índia & 0 & 8 & 5 & 12 & 500.0 & 50.0 & 0.00 & 0.33 & 0.33 & 0.77 & 3300.0 & 135.2 & 0.10 & 0.19 & 90.44 & & & -66.67 & 0.00 & 0.05 & & 0 & 1 & \\
\hline Rússia & 10 & 10 & 13 & 8 & 30.0 & -20.0 & 0.71 & 0.50 & 1.16 & 0.50 & 62.3 & \begin{tabular}{c|c|}
-0.2 \\
\end{tabular} & 0.03 & 0.08 & \begin{tabular}{c|c|}
185.97 \\
\end{tabular} & & & 800.00 & 0.48 & 0.94 & 95.24 & 5 & 9 & 80.00 \\
\hline México & 7 & 5 & 3 & 6 & -57.1 & $\begin{array}{l}20.0 \\
\end{array}$ & 0.26 & $\begin{array}{ll}0.67 \\
\end{array}$ & 0.13 & 0.90 & -48.7 & $\begin{array}{l}34.2 \\
\end{array}$ & $\begin{array}{l}0.11 \\
\end{array}$ & 0.24 & $\begin{array}{l}127.47 \\
\end{array}$ & & 1 & 0.00 & $\begin{array}{l}0.09 \\
\end{array}$ & 0.09 & \begin{tabular}{l|l|}
2.04 \\
\end{tabular} & 2 & 1 & -50.00 \\
\hline \begin{tabular}{|l|} 
Coréía \\
\end{tabular} & 9 & 17 & 7 & 19 & -22.2 & $\begin{array}{ll}11.8 \\
\end{array}$ & 0.46 & $\begin{array}{ll}1.93 \\
\end{array}$ & 0.33 & 2.65 & $\begin{array}{l}-27.7 \\
\end{array}$ & \begin{tabular}{ll|}
37.2 \\
\end{tabular} & 0.30 & 0.52 & 70.86 & 5 & 6 & -40.00 & 0.17 & 0.10 & $\begin{array}{l}-42.72 \\
\end{array}$ & 3 & 3 & 0.00 \\
\hline Média PeD & 6 & 11 & 8 & 15 & $\begin{array}{l}38.9 \\
\end{array}$ & $\begin{array}{l}34.3 \\
\end{array}$ & 0.31 & 0.92 & 0.64 & 2.04 & $\begin{array}{l}109.1 \\
\end{array}$ & \begin{tabular}{|l|l|}
121.7 \\
\end{tabular} & \begin{tabular}{l|l|}
0.15 \\
\end{tabular} & 0.48 & \begin{tabular}{|l|}
223.82 \\
\end{tabular} & 3 & 5 & 35.29 & 0.15 & \begin{tabular}{l|l|}
0.29 \\
\end{tabular} & \begin{tabular}{|l|l|}
91.25 \\
\end{tabular} & 2 & 4 & 76.92 \\
\hline EUA & 20 & 30 & 24 & 31 & 20.0 & \begin{tabular}{|r|}
3.3 \\
\end{tabular} & $\begin{array}{l}5.82 \\
\end{array}$ & $\begin{array}{l}8.07 \\
\end{array}$ & 4.50 & 5.38 & $\begin{array}{r}-22.7 \\
\end{array}$ & -33.3 & 1.76 & 1.24 & -29.40 & 11 & 11 & -18.18 & 1.96 & 1.41 & \begin{tabular}{|c|}
-27.91 \\
\end{tabular} & 8 & 9 & 12.50 \\
\hline Japão & 9 & 29 & 6 & 25 & \begin{tabular}{|l|} 
\\
\end{tabular} & $\begin{array}{l}-13.8 \\
\end{array}$ & 1.68 & 6.65 & 1.03 & 3.80 & \begin{tabular}{|l|l|} 
& -38.4 \\
\end{tabular} & \begin{tabular}{|l|}
-42.8 \\
\end{tabular} & 1.26 & 0.64 & -48.75 & 8 & 7 & -87.50 & $\begin{array}{l}0.59 \\
\end{array}$ & 0.45 & \begin{tabular}{|l|}
-24.18 \\
\end{tabular} & 2 & 1 & -50.00 \\
\hline Alemanha & 16 & 31 & 12 & 30 & -25.0 & \begin{tabular}{|l|}
-3.2 \\
\end{tabular} & 1.14 & 8.12 & 1.34 & 5.98 & \begin{tabular}{|l|l|}
17.3 \\
\end{tabular} & -26.4 & 1.76 & 1.32 & -24.78 & 9 & 8 & -55.56 & 0.33 & 0.36 & \begin{tabular}{|l|}
8.37 \\
\end{tabular} & \begin{tabular}{l|l}
5 \\
\end{tabular} & 4 & -20.00 \\
\hline França & 15 & 20 & 9 & 19 & -40.0 & \begin{tabular}{|c|}
-5.0 \\
\end{tabular} & 1.22 & 3.80 & 0.60 & 2.23 & \begin{tabular}{|l|} 
\\
\end{tabular} & \begin{tabular}{|l|}
-41.3 \\
\end{tabular} & 0.78 & 0.55 & -28.80 & 6 & 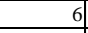 & \begin{tabular}{|c|c|c|}
-667 \\
\end{tabular} & $\begin{array}{l}0.40 \\
\end{array}$ & 0.12 & \begin{tabular}{|c|}
-69.69 \\
\end{tabular} & 3 & 2 & -60.00 \\
\hline Itália & 12 & 23 & 6 & 18 & -50.0 & \begin{tabular}{|l|}
-21.7 \\
\end{tabular} & $\begin{array}{l}0.67 \\
\end{array}$ & 2.90 & 0.38 & 1.80 & -43.6 & \begin{tabular}{|c|}
-37.8 \\
\end{tabular} & 0.56 & 0.41 & -28.19 & 6 & 6 & -66.67 & 0.23 & 0.11 & \begin{tabular}{|c|}
-49.71 \\
\end{tabular} & 4 & 2 & -50.00 \\
\hline Reino Unido & 11 & 21 & 13 & 14 & $\begin{array}{l}18.2 \\
\end{array}$ & \begin{tabular}{|l|}
-33.3 \\
\end{tabular} & 1.21 & 3.30 & 1.71 & 1.45 & 42.1 & \begin{tabular}{|l|}
-56.1 \\
\end{tabular} & 0.76 & 0.39 & -48.12 & 6 & $f$ & -50.00 & 0.24 & 0.35 & \begin{tabular}{|l|l|}
41.62 \\
4
\end{tabular} & \begin{tabular}{l|l}
3 \\
3
\end{tabular} & 3 & 0.00 \\
\hline \multirow[t]{4}{*}{ Média PD } & 14 & & 12 & 23 & \begin{tabular}{|c|}
-15.7 \\
\end{tabular} & \begin{tabular}{|c|}
-11.0 \\
\end{tabular} & 1.96 & 5.47 & 1.59 & 3.44 & -18.5 & \begin{tabular}{|l|}
-37.1 \\
\end{tabular} & 1.15 & 0.76 & $\mid-33.65$ & 8 & 7 & -54.35 & \begin{tabular}{|l|l|}
0.63 \\
\end{tabular} & 0.47 & -25.26 & 5 & 4 & -22.22 \\
\hline & \multicolumn{6}{|c|}{ Número de Ligações - Importações - LIMP } & \multicolumn{6}{|c|}{ Participação nas Importações - PIMP } & \multicolumn{6}{|c|}{ IT Importa dos Serviços - IIMS } & \multicolumn{6}{|c|}{ Serviços Importa da IT - SIMPI } \\
\hline & \multicolumn{2}{|c|}{1995} & 20 & & Variac & $(\%)$ & 199 & & 201 & & Variaç: & (\%) & Participaçã & o nas Imp & ortações & Núm & ero de Lig & gações & Participa & ז̃̃o nas In & nportações & Núme & ero de Lig & zações \\
\hline & Se & IT & $\mathrm{Se}$ & IT & Se & IT & Se & IT & $\mathrm{Se}$ & IT & Se & IT & 1995 & 2010 & \begin{tabular}{|l|l|}
$\operatorname{Var}(\%)$ \\
\end{tabular} & 1995 & 2010 & \begin{tabular}{|l|l|}
$\operatorname{Var}(\%)$ \\
\end{tabular} & 1995 & 2010 & $\operatorname{Var}(\%)$ & 1995 & 2010 & $\operatorname{Var}(\%)$ \\
\hline Brasil & 7 & 9 & 10 & 11 & 42.9 & 22.2 & 0.26 & 0.55 & 0.39 & 0.66 & 50.8 & 21.8 & 0.00 & 0.02 & & 0 & & & 0.11 & 0.13 & 12.03 & 4 & 4 & 0.00 \\
\hline China & 7 & 13 & 15 & 24 & 114.3 & 84.6 & 0.40 & 1.84 & 1.51 & 8.03 & 273.7 & 336.1 & 0.03 & 0.52 & 1652.36 & 1 & & 400.00 & 0.34 & 0.87 & 154.35 & 5 & 6 & 20.00 \\
\hline Índia & 2 & 7 & 3 & 9 & $\begin{array}{l}50.0 \\
\end{array}$ & 28.6 & $\begin{array}{l}0.09 \\
\end{array}$ & $\begin{array}{l}0.43 \\
\end{array}$ & 0.35 & 1.35 & 301.4 & 215.1 & 0.02 & 0.04 & 68.27 & 1 & & 0.00 & 0.07 & 0.35 & \begin{tabular}{|l|l|}
430.08 \\
\end{tabular} & 1 & 3 & 200.00 \\
\hline Rússia & 4 & 4 & 7 & 6 & \begin{tabular}{ll|}
75.0 \\
\end{tabular} & \begin{tabular}{l|l}
50.0 \\
\end{tabular} & 0.16 & 0.25 & 0.24 & 0.27 & 51.0 & \begin{tabular}{l|l|}
8.0 \\
\end{tabular} & 0.00 & 0.00 & & 0 & 0 & & 0.12 & 0.16 & 29.64 & 3 & 4 & 33.33 \\
\hline México & 1 & 6 & 5 & 8 & 400.0 & \begin{tabular}{|l|}
33.3 \\
\end{tabular} & $\begin{array}{ll}0.19 \\
\end{array}$ & 0.92 & 0.32 & 1.05 & 70.4 & \begin{tabular}{l|l|}
13.4 \\
\end{tabular} & 0.00 & 0.00 & & 0 & 0 & & \begin{tabular}{l|l|}
0.19 \\
\end{tabular} & 0.29 & \begin{tabular}{|l|l|}
53.49 \\
\end{tabular} & 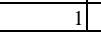 & 4 & 300.00 \\
\hline \begin{tabular}{|l|} 
Coréia \\
\end{tabular} & 9 & 17 & 9 & 17 & $\begin{array}{l}0.0 \\
\end{array}$ & 0.0 & $\begin{array}{l}0.38 \\
\end{array}$ & $\begin{array}{l}2.09 \\
\end{array}$ & 0.58 & 2.45 & 51.8 & $\begin{array}{l}17.5 \\
\end{array}$ & 0.10 & 0.21 & 111.89 & 3 & 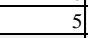 & 66.67 & 0.20 & 0.21 & $\begin{array}{l}3.58 \\
\end{array}$ & 4 & 4 & 0.00 \\
\hline Média PeD & 5 & 9 & 8 & 13 & $\begin{array}{l}63.3 \\
\end{array}$ & $\begin{array}{l}33.9 \\
\end{array}$ & 0.25 & 1.01 & 0.57 & 2.30 & 129.0 & $\begin{array}{ll}127.3 \\
\end{array}$ & 0.03 & 0.13 & 418.12 & 1 & 2 & 140.00 & 0.17 & 0.33 & \begin{tabular}{|l|l|}
93.68 \\
\end{tabular} & 3 & 4 & 38.89 \\
\hline EUA & 25 & 23 & 25 & 25 & $\begin{array}{l}0.0 \\
\end{array}$ & 8.7 & 3.98 & 8.11 & 4.65 & $\begin{array}{l}6.22 \\
\end{array}$ & 16.7 & -23.4 & 0.66 & 0.46 & \begin{tabular}{|l|} 
\\
\end{tabular} & 6 & 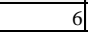 & 0.00 & 2.02 & 2.36 & \begin{tabular}{|l|l|}
17.17 \\
\end{tabular} & 12 & 12 & 0.00 \\
\hline Japão & 18 & 20 & 12 & 16 & \begin{tabular}{|l|}
-33.3 \\
\end{tabular} & \begin{tabular}{|c|}
-20.0 \\
\end{tabular} & $\begin{array}{l}1.63 \\
\end{array}$ & 3.52 & 1.10 & 2.66 & -32.4 & $\begin{array}{l}-24.5 \\
\end{array}$ & 0.30 & 0.25 & -17.21 & 4 & 5 & 25.00 & 0.64 & 0.38 & -40.06 & 7 & 5 & -28.57 \\
\hline \begin{tabular}{|l} 
Alemanha \\
\end{tabular} & 19 & 23 & 18 & 23 & \begin{tabular}{|l|} 
\\
\end{tabular} & 0.0 & 1.90 & 5.26 & 1.59 & 4.22 & -16.2 & \begin{tabular}{|c|}
-19.7 \\
\end{tabular} & 0.49 & 0.34 & -29.77 & 7 & 6 & -14.29 & 0.89 & 0.75 & \begin{tabular}{|l|l|}
-15.62 \\
\end{tabular} & 7 & 9 & 28.57 \\
\hline França & 17 & 16 & 13 & 16 & -23.5 & 0.0 & 1.61 & 2.88 & 0.90 & \begin{tabular}{l|l|}
2.19 \\
\end{tabular} & -44.1 & \begin{tabular}{|l|}
-23.9 \\
\end{tabular} & 0.25 & 0.18 & -26.84 & 6 & t & -33.33 & $\begin{array}{l}0.78 \\
\end{array}$ & 0.48 & \begin{tabular}{|c|}
-38.11 \\
\end{tabular} & 7 & 7 & 0.00 \\
\hline Itália & 15 & 19 & 13 & 15 & \begin{tabular}{|l|}
-13.3 \\
\end{tabular} & -21.1 & $\begin{array}{l}1.10 \\
\end{array}$ & $\begin{array}{l}2.63 \\
\end{array}$ & 1.15 & \begin{tabular}{l|l}
1.82 \\
\end{tabular} & 3.8 & \begin{tabular}{|l|}
-30.8 \\
\end{tabular} & 0.27 & 0.23 & -15.01 & 6 & 5 & \begin{tabular}{|c|}
-16.67 \\
\end{tabular} & 0.56 & 0.39 & \begin{tabular}{|l|}
-29.99 \\
\end{tabular} & 6 & 5 & $\begin{array}{l}-16.67 \\
\end{array}$ \\
\hline Reino Unido & 15 & 13 & 17 & 13 & $\begin{array}{l}13.3 \\
\end{array}$ & \begin{tabular}{ll|}
0.0 \\
\end{tabular} & $\begin{array}{l}1.72 \\
\end{array}$ & 2.51 & 1.76 & \begin{tabular}{l|l}
1.23 \\
\end{tabular} & 2.6 & $\begin{array}{l}-51.2 \\
\end{array}$ & 0.12 & 0.09 & -24.14 & 2 & 3 & 50.00 & 0.96 & $\begin{array}{l}0.78 \\
\end{array}$ & \begin{tabular}{|l|l|}
-18.76 \\
\end{tabular} & 7 & 8 & 14.29 \\
\hline Média PD & 18 & 19 & 16 & 18 & \begin{tabular}{|l|}
-10.1 \\
\end{tabular} & \begin{tabular}{|c|}
-5.3 \\
\end{tabular} & \begin{tabular}{|l|}
1.99 \\
\end{tabular} & 4.15 & 1.86 & 3.06 & $\begin{array}{l}-6.7 \\
\end{array}$ & \begin{tabular}{|l|}
-26.4 \\
\end{tabular} & 0.35 & 0.26 & -25.46 & 5 & S & $\mid-6.45$ & 0.97 & 0.86 & -11.85 & 8 & 8 & 0.00 \\
\hline
\end{tabular}

Tabela 4 - Indicadores tradicionais de Redes dos Países Selecionados

Fonte: World Input-Output Database (WIOD). Elaborado pelo autor a partir do software Pajek.

Notas: (1) A média dos Países desenvolvidos (PDs) e em desenvolvimento (PeDs) contemplam apenas os países da amostra. (2) Os valores de Exportação e Importações não são iguais na tabela, pois não estão considerando os Outros PD e Outros PeD. 
Esses resultados caracterizam o sucesso das políticas historicamente voltadas ao mercado externo no país. Para Rodrik $(2014 ; 20)$ a experiência japonesa foi o modelo para outros países do Leste e Sudeste Asiático, principalmente, Coreia e China. Embora eles tenham utilizados instrumentos de política industrial diferentes, "a principal característica é o modelo de industrialização orientada para a exportação, obtida por meio da combinação entre empreendedorismo do setor privado e incentivos governamentais".

A Índia (IN) e Rússia (RU) apresentam mudanças pontuais com relação às exportações de serviços. A Índia, reconhecida como um grande produtor de software (ASPRAY et al., 2009), destacou-se na exportação de Serviços, a participação relativa aumentou de $0,0 \%$ para $0,33 \%$ das exportações mundiais no período. Na Rússia (RU) também houve crescimento nas vendas externas de serviços, mas com variação menor possivelmente alavancado pelos serviços de distribuição de gás e petróleo, favorecida por sua posição geográfica e importância desta atividade.

O Brasil (BR) exibiu uma pequena variação negativa nos elos e na participação relativa das exportações da IT, mas ambas positivas para os serviços. Em grande medida esse aumento está relacionado à exportação de serviços para indústria (SEXPI, que aumentou de $0,03 \%$ para $0,09 \%$ das exportações mundiais em 2010). Todavia, em termos gerais, o país tem números abaixo da média dos demais PeD. Por outro lado, a variação foi positiva em todos os indicadores para as importações, aumentando o número de países fornecedores (elos) e a participação nas compras externas de bens industriais e de serviços. Em síntese, tanto nas exportações como nas importações o Brasil apresenta indicadores com valores superiores apenas aos da Rússia, demonstrando pouca interação nos fluxos de comércio internacional. No conjunto, confrontados os resultados das exportações vis à vis as importações parecem indicar que a estratégia das empresas estabelecidas no país pode ser carcaterizada por "explorando" o mercado nacional.

Nos PD algumas evidências são significativas das mudanças internacionais recentes. Na Indústria de Transformação todos os países apresentaram variações negativas nos elos externos (LEXP; exceto EUA na IT) e na proporção relativa das exportações (PEXP; exceto Alemanha e Reino Unido nos Serviços). Outro destaque importante é que, mesmo com a ascensão da participação dos Serviços nestas economias, todos os outros PDs da amostra (exceto Reino Unido) mantêm a maior parte da sua pauta de exportação concentrada em bens industriais - na média dos países selecionados, a proporção desse agregado representa 2,15 vezes a mais que o do Serviços. Essa característica parece reforçar a importância deste setor para estas economias e corroborar a hipótese central deste estudo.

Essa diferença é ainda mais marcante em países reconhecidos pela produção de bens industriais de alta intensidade tecnológica,-- por exemplo, Alemanha (3,7 vezes) e Japão (4,5 vezes). Não por acaso, as exportações da indústria para serviços (IEXPS) e as importações de serviços para indústrias (SIMPI) permanecem em valores elevados nos PD. Esses resultados indicam que a "especialização nacional em serviços" deve ser pensada com ressalvas, mas, certamente, por meio das cadeias globais de valor. Em particular, os EUA (UN) se mantiveram como o ator mais importante no comércio internacional, mesmo com variações negativas na participação relativa tanto nos Serviços como na indústria. $O$ país aumentou o número de elos de exportação, compondo os fluxos de comércio com um número maior de países.

Os resultados desta seção confirmam o aumento da participação dos $\mathrm{PeD}$ nos fluxos comerciais, mas mostram também a concentração da China neste processo, tanto na exportação e importação da indústria e Serviços. Em praticamente todos os $\mathrm{PeD}$, as variações nos fluxos de Serviços foram mais elevadas do que na indústria, mas, em geral, o número de elos e a participação no comércio internacional são inferiores. Ou seja, em 
termos relativos a pauta de comércio destes países avançou mais nos Serviços do que na IT, mas ainda é composta majoritariamente de bens industriais. Paralelamente, os PD exibiram quedas na maioria dos indicadores, mas ainda concentram a maior parte dos fluxos comerciais e a supremacia nas participações das relações entre indústria e serviços.

\section{Considerações finais}

Os resultados confirmam as transformações no comércio internacional relacionadas ao direcionamento (países), magnitude (valores) e pauta (setor de serviços). A desconcentração desse comércio é motivada pela entrada dos $\mathrm{PeD}$ nas $\mathrm{CGV}$, tanto como fornecedores de bens industriais para PeD e PD, como consumidores de Serviços dos PD. A pauta de comércio destes países avançou em termos relativos mais nos serviços do que na IT, mas ainda é formada majoritariamente de bens industriais. Adicionalmente, a IT tem alavancado o comércio internacional dos Serviços para a maioria dos países da amostra, principalmente para os PD, que em alguns casos (especialmente Reino Unido e EUA) têm se especializado nessas atividades.

No entanto, afora o papel histórico dos EUA, parte substantiva dessas mudanças é devido ao papel da China neste processo, tanto nos fluxos comerciais da IT, como nos Serviços. Os resultados parecem indicar certo nível de "adaptação" nos movimentos dos fluxos comerciais dos dois países que conduzem à atual divisão internacional do trabalho: (i) os dois países exibem elevadas importações de Recursos Naturais dos PeD e de Serviços dos PD; (ii) a China atua como fornecedora de bens industrializados para PeD e PD; e (iii) os EUA se especializam em exportações de Serviços para $\mathrm{PeD}$ e, principalmente, para PD. No entanto, algumas evidências mostram que a China parece caminhar nesta mesma direção, ou seja, confrontar os EUA na sua especialização.

A avaliação realizada neste artigo mostra também aspectos importantes relacionados com a Coreia e Brasil. Entre eles, uma questão se sobressai: como os países se posicionaram com o crescimento chinês? A Coreia aparece como principal destino das exportações e origem das importações entre os PeD. O Brasil concentra a importação de produtos industriais para os setores da IT e Serviços, e atua como fornecedor de Recursos Naturais.

Podemos atribuir as diferenças nos desempenhos da China e Coreia em relação ao Brasil aos resultados das políticas industriais bem-sucedidas realizadas em mais de uma década e que combinaram incentivos governamentais e empreendedorismos privados (BALDWIN, 2011; GEREFFI e STURGEON, 2013; RODRIK, 2014). Esse estudo parece corroborar com este entendimento uma vez que os dois países asiáticos se mantêm competitivos na IT (elevação da participação das exportações) e a China nos Serviços (idem), enquanto os indicadores brasileiros permanecem muito reduzidos.

\section{Referências Bibliográficas}

ANTONELLI, C. Localized technological change, new information technology and the knowledge-based economy: the European evidence. Journal of evolutionary economics, v. 8, n. 2, p. 177-198, 1998.

ARBACHE, J. Serviços e competitividade industrial no Brasil. Confederação Nacional da Indústria - Brasília: Confederação Nacional da Indústria, 2014.

ARBACHE, J. Por que serviços? in "Indústria e Desenvolvimento Produtivo no Brasil", Orgs. N. Barbosa, N. Marconini. M.C. Pinheiro e L. Carvalho, São Paulo: Elsevier e FGV, 2015. 
ASPRAY, W; MAYADAS, F; VARDI, M. Y. 3. Globalization and ofshoring of software. Innovation Imperative: National Innovation Strategies in the Global Economy, p. 24, 2009.

BALDWIN, R. Trade and industrialisation after globalisation's 2nd unbundling: How building and joining a supply chain are different and why it matters. National Bureau of Economic Research, 2011.

CERNAT, L; KUTLINA-DIMITROVA, Z. Thinking in a box: A 'mode 5' approach to service trade. Journal of World Trade, v. 48, n. 6, p. 1109-1126, 2014.

CHESNAIS, F. A mundialização do capital. Xamã, 1996.

DUNNING, J. H. Re-evaluating the benefits of foreign direct investment. Transnational corporations, v. 3, n. 1, p. 23-51, 1994.

DUNNING, J. H.; LUNDAN, S. M. Multinational enterprises and the global economy. Edward Elgar Publishing, 2008.

GEREFFI, G. The Organization of Buyer-Driven Global Commodity Chains: How US Retailers Shape Overseas Production Networks. Commodity chains and global capitalism, 1994.

GEREFFI, G., HUMPHREY, J., e KAPLINSKY, R. Introduction: Globalisation, value chains and development. IDS bulletin, 32(3), 1-8.2001.

GEREFFI, G; HUMPHREY, J; STURGEON, T. The governance of global value chains. Review of international political economy, v. 12, n. 1, p. 78-104, 2005.

GEREFFI, G; STURGEON, T. 14 Global value chain-oriented industrial policy: the role of emerging economies. Global value chains in a changing world, p. 329, 2013.

GOMES, R. Empresas Transnacional e Internacionalização da P\&D: elementos de organização industrial da economia da inovação. São Paulo, Editora da Unesp, 2006

GOYAL, S. Connections: An Introduction to the Economics of Networks, Princeton University Press, Princeton and Oxford. 2007.

HIRATUKA, C. Empresas transnacionais e comércio exterior: uma análise das estratégias das filiais brasileiras no contexto da abertura econômica. 2002.

IETTO-GILLIES, G. Transnational Corporations and International Production: Concepts, Theories and Effects, second edition. Cheltenham, UK. Edward Elgar Publishing, 2012

LOW, P. 2 The role of services in global value chains. Global value chains in a changing world, p. 61, 2013

LUNDVALL, B. National innovation systems - analytical concept and development tool. Industry and innovation, v. 14, n. 1, p. 95-119, 2007.

MANYIKA, J. Manufacturing on future: The next era of global growth and innovation. McKinsey \& Company. Nov 2012.

OECD. Chapter 7 - Upgrading in global value chains: The role of knowledge-based capital. Interconnected Economies: Benefiting from Global Value Chains. OECD Publishing, 2013.

RODRIK, D. The past, present, and future of economic growth. Challenge, v. 57, n 3, p. 5-39, 2014.

SARTI, F.; HIRATUKA, C. Indústria mundial: mudanças e tendências recentes. Campinas: Unicamp. IE, 2010. 
SAVIOTTI, P.P. Chapter 2 - Knowledge Networks: Structure and Dynamics. In A. Pyka, A. Scharnhorst (eds.), Innovation Networks, Understanding Complex Systems, DOI 10.1007/978-3-540-92267-4 2, C Springer-Verlag Berlin Heidelberg. 2009.

SCHETTKAT, R.; YOCARINI, L. The shift to services employment: A review of the literature. Structural Change and Economic Dynamics 17.2 (2006): 127-147. 2006.

SCHWEITZER, F., FAGIOLO, G., SORNETTE D., VEGA-REDONDO, F. E WHITE, D. Economic Networks: What Do We Know And What Do We Need To Know?. Advances in Complex Systems: A Multidisciplinary Journal. Volume 12, Issue 04n05, August \& October 2009.

TIMMER, M.P., A.A. ERUMBAN, B. LOS, R. STEHRER e G. DE VRIES, New Measures of European Competitiveness: A Global Value Chain Perpsective, World InputOutput Database, Working Paper No. 9. 2012

TIMMER, M. P., DIETZENBACHER, E., LOS, B., STEHRER, R., \& VRIES, G. J. An illustrated user guide to the world input-output database: the case of global automotive production. Review of International Economics, 23(3), 575-605. 2015.

UNCTAD, FDI from Developing and Transition Economies: Implications for Development, World Investment Report 2006, Geneva: United Nations. 2006.

UNCTAD, United Nations Conference on Trade and Development. World Investment Report 2007 - Transnational Corporations, Extractive Industries and Development. 2007.

UNCTADSTAT, http://unctadstat.unctad.org/ReportFolders/reportFolders.aspx. 2013.

WIOD, World Input-Output Database, disponível em: http://www.wiod.org/new_site/home.htm. 2014 